\title{
The attitudes and experiences of families with death determination in the home
}

\author{
Susan H. Critz, MS, RN
}

\section{Abstract}

The purpose of this study is to describe the attitudes and experiences of family members with respect to death determination practices for the terminally ill clients of home care agencies. A sample of family $53 \mathrm{mem}$ bers in Southeast Michigan returned survey questionnaires. The findings indicate that police and emergency medical technicians most frequently respond to the call when a person with a terminal illness has died. Fifty percent of the family members reported feeling sad, 35 percent reported feeling relieved and 18 percent of the respondents felt angry about the arrival of municipal personnel.Feelings of anger were significantly associated with the absence of a nurse at the time of death, the use of lights and sirens, disrespectful personnel and the arrival of multi-

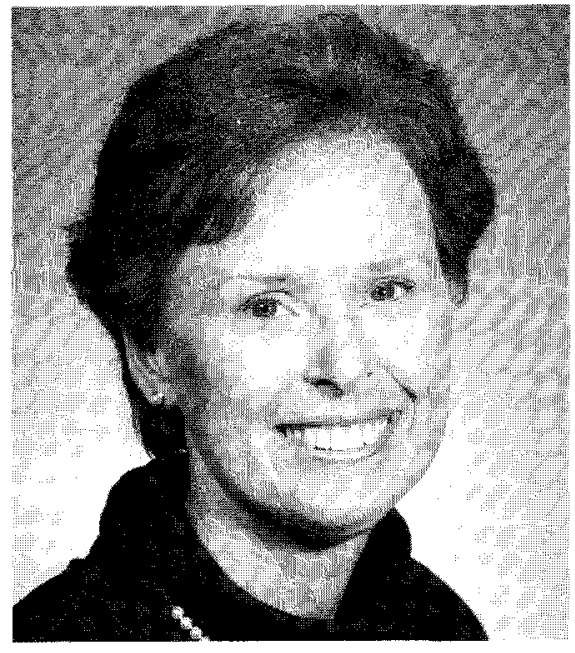

Susan H. Critz, MS, RN is Assistant Head Nurse for Internal Medicine Outpatient Services at the University of Michigan Hospitals, Ann Arbor, Michigan. ple personnel. Feelings of anger were also significantly associated with continuing thoughts of the day of death by family members. Results suggest the need to rethink state and local laws in regard to death determination and to educate those most likely to respond to families sensitively. Home care agencies and hospices should also encourage attendance by nurses at the time of death.

\section{Introduction}

Increasing difficulty in admission to acute care facilities, earlier discharges, limited extended care facilities, the increasing size of the elderly cohort, and personal preferences contribute to projections for an increase in the number of deaths that will occur at home. ${ }^{1}$ Hospice and home care programs are serving an increasing number of terminally ill patients whose deaths occur at home.

Most state laws regarding pronouncement and certification of death were written either during the years when physicians made visits to private homes or under the assumption that all deaths occurred within easy access to a physician. Public health codes were developed particularly to meet the need when deaths occur suddenly, accidentally, violently or unexpectedly. ${ }^{2}$ A key question to answer is whether the same law should apply to pronouncement and certification of deaths that occur in a private residence when the death is anticipated and care has been provided by a nursing agency during the period of the illness leading to the death.

\section{Background}

Little research has been completed on the family as a system at the time of death of a member. ${ }^{3}$ Woodhall reported that terminal care and death at home tends to occur only in those circumstances where the ill person has full family support, good symptom control and positive mental attitudes. ${ }^{4}$ Kirschling's study of the care givers of the terminally ill suggests that support for family care givers derives from interpersonal relationships within and outside the family. ${ }^{5}$

$$
\begin{gathered}
\text { It appears } \\
\text { that any one } \\
\text { or a combination } \\
\text { of individuals } \\
\text { (nurse, doctor, } \\
\text { medical examiner, } \\
\text { police, fire or } \\
\text { emergency personnel) } \\
\text { may attend or } \\
\text { respond to a } \\
\text { death in } \\
\text { the home. }
\end{gathered}
$$

Research linking bereavement outcome for survivors of a death is inconclusive. ${ }^{6,7,8}$ Parkes has begun to analyze the various research results to identify risk factors related to difficulty in the experience of bereavement for individuals. ${ }^{9} \mathrm{He}$ has found that type of death, suddeness of death, and the untimely, unexpected, painful, horrifying 
or mismanaged nature of the death can be significant risk factors influencing bereavement outcome.

In devising research based on the memory of an event, clarity of memory and time since the event are important variables. Sudman and Bradburn suggest that memory is related to time and saliency. ${ }^{10}$ The more important the event, the easier it is for a respondent to remember. Bugen's study on the intensity and duration of grief suggests that a survey of survivors should not be done until two months after a death due to the depression experienced by survivors. ${ }^{11}$ Another factor which must be considered in a survey of survivors is that of anniversary reactions. Pollock and Mintz have documented that increased stress is experienced by survivors at certain times of the day, days of the month, seasons, festivals, birthdays or holidays. ${ }^{12,13} \mathrm{~A}$ study of surviving hospice significant others by Kane, Klein, Bernstein and Rothenberg added support to the theory of anniversary reactions. ${ }^{14}$ Their analysis of 150 significant others indicated the highest levels of anxiety and depression at six weeks after the death. Levels decreased through eighteen months with a single slight rise at one year.

\section{The family \\ members who \\ shared their \\ feelings about \\ the arrival of \\ emergency personnel \\ most often \\ reported feelings of \\ sadness.}

Family demographic variables have been investigated for significant differences in bereavement patterns. Lundin reported that women try less hard to avoid thinking about the deceased. ${ }^{15}$
Also, he found that it was easier for those whose loss was the result of a disease to talk about the dead person without discomfort than for those whose loss was sudden or unexpected.

\section{Research question and operational definitions}

Based on the documented increase in hospice care and deaths in the home, it is important to address the concerns of the surviving families about the determination of death. ${ }^{16,17}$ Using a survey methodology, the following questions were addressed:

- What are practices for the determination of death for terminally ill home care clients as reported by the family members of recently deceased clients?

- What is the attitude of family members of recently deceased clients about the arrival of emergency personnel into the home at the time of death and/or the transport of deceased clients to area hospitals for the determination of death by a physician?

- Are there demographic factors which are related to the attitudes of family members of recently deceased clients about death determination practices?

Terminal illness was understood to be an advanced disease process which cannot be reversed. The course of the disease is one which results in death.

This study defined determination of death as the legal determination of death based on the irreversible cessation of spontaneous respiratory and circulatory functions. Respondents were instructed to consider death pronouncement as equivalent to determination of death.

The attitudes of family members were operationalized based on the conceptualization of attitudes by Ajzen and
Fishbein to be a composite of beliefs, feelings, and behavioral intentions. ${ }^{18}$

All references to nurses within this study refer to Michigan licensed registered nurses employed by a home care agency, and functioning with clients and their families in their homes.

\section{An important opportunity exists for nurses to share their knowledge about the impact of the death experience on families with physicians and emergency personnel.}

A family member is any relative of the terminally ill client by blood or marriage, present at the time of death.

Methods

\section{Design and sample}

This descriptive study was part of a larger study designed to include those most affected by the current death pronouncement procedures for deaths in the home - physicians, home health care nurses, and family members. Data were collected by mailed questionnaires from a sample of family members from three Medicare certified home care agencies in Southeast Michigan. The agencies were chosen based on the fact that they were known to serve a large number of terminally ill clients. The data from family members were gathered from a single family member for each of ninety home care clients (thirty from three agencies) who had died at home within the period of two to ten months before the date of questionnaire mailing. Questionnaires were not sent to those randomly selected family members at the time of a major holiday or to those where it 
could be determined that the questionnaire would be answered within two weeks of the birthday of the deceased.

\section{Instrument}

A questionnaire was developed for this study based on a literature review and the clinical experiences of home care nurses in Southeast Michigan. A family member received a questionnaire developed specifically to elicit their attitudes about the determination of death for terminally ill clients in the home. Consistent with the concept of attitude, the questionnaires explored beliefs, opinions, and feelings about current practice. Each questionnaire also requested relevant demographic information which might influence attitude or experience with death determination.

Content validity of the instrument was ascertained by review of the questionnaire by five professional home care nurses and four graduate nursing faculty members.

\section{Procedure}

Each agency which provided access to the sample groups was approached first by telephone about participation. Those agencies indicating interest received a written proposal for Internal Review Board decision. Each agency

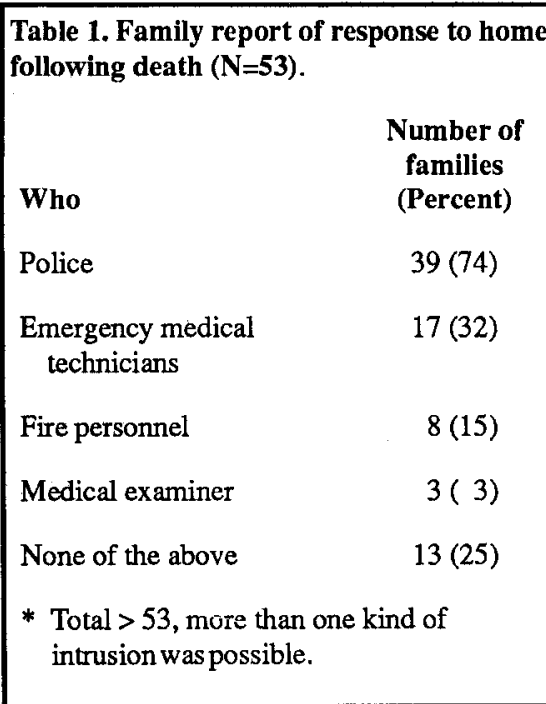

Figure 1. Family member response to intrusion $(\mathrm{N}=40)$.

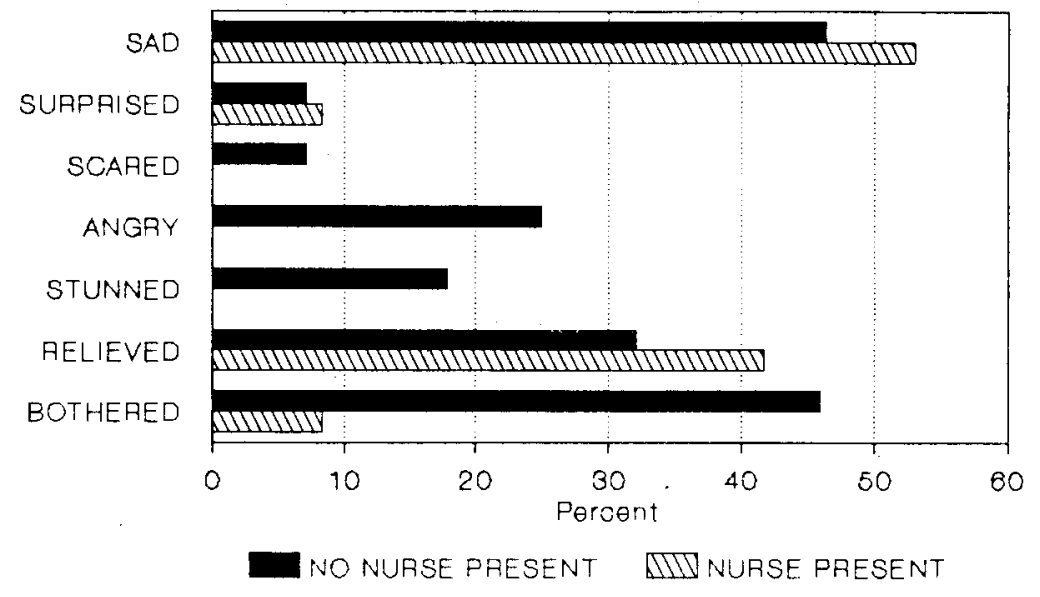

was asked to indicate those clients known to have died at home two to ten months prior to the date of mailing. Each client was assigned a number from the random number chart. The first thirty clients in each agency assigned an odd number where the chart indicated a mailing address for a spouse or family member was mailed the questionnaire. If a chart provided several names of kin and addresses, the surviving spouse received the questionnaire. In the absence of a spouse, the questionnaire was sent to the first kin listed in the chart with an address.

Table 2. Reported family feelings about intrusion $(\mathrm{N}=40)$.

\section{Data analysis of specific research questions}

\section{Current practices}

A family member was asked to recall the day of the death of the client from the surveyed agencies. All of the respondents $(\mathrm{N}=53)$ reported remembering that day two to ten months ago. In fact, ninety-six percent $(\mathrm{N}=51)$ described remembering that day vivid1y. The experience of these families in relation to intrusion is summarized in Table 1. Most families experienced a visit by police and emergency units.

Only two family members in the sample responded to the questions about transport. Both respondents 
Table 3. Significant associations with feelings of anger (N=40)

\begin{tabular}{|lccc}
\multicolumn{1}{c}{ Factors } & $\mathbf{X}^{2}$ & $\mathbf{d f}$ & $\mathbf{p}$ \\
Disrespectful personnel & 6.43 & 1 & .01 \\
Lights and sirens & 5.24 & 1 & .02 \\
Multiple persons & 464 & 1 & .03 \\
Sadness & 4.33 & 1 & .04 \\
Absence of RN & 3.63 & 1 & .05 \\
Continuing thoughts & 3.80 & 1 & .05 \\
Male sex & 2.98 & 1 & .08 \\
\hline
\end{tabular}

reported a cost of fifty dollars or more for this service. This fee was not reimbursed by insurance. One other family member indicated that the body was supposed to be transported but the family had refused.

Family members reported that a registered nurse was present at the time of death for nineteen cases (36 percent). Additionally, a nurse came to help immediately after the death in sixteen more cases. In total, a registered nurse either attended or arrived shortly after the death in 35 of the total 53 cases (66 percent).

\section{Bereavement counseling by nurses or others must take into account that survivors have vivid memories of the day of death after ten months.}

\section{Attitudes about current practices}

Forty family members shared their attitudes about death determination practices, based on their experience with the arrival of emergency personnel. The predominant emotion was that of sadness. Still, more than one-third reported relief at the arrival of the police, fire or emergency personnel (Table 2). Figure 1 displays the dramatic difference in family response based on the presence of a nurse at the time of death when the arrival of municipal authorities occurs. The absence of a nurse was significantly related to reports of being bothered by emergency personnel $\left(\mathrm{X}^{2}=5.36, \mathrm{df}=\right.$ $1, \mathrm{p}=.02)$ and anger $\left(\mathrm{X}^{2}=3.63, \mathrm{df}=\right.$ $1, \mathrm{p}=.056)$.

Thirty-five percent of the family members $(n=14)$ indicated that they found the intrusion bothersome. The sight of the vehicles outside the home $(n=10)$, and to a lesser extent, the questioning $(\mathrm{n}=7)$ and the lights and sirens $(n=6)$ were the primary causes for concern.

Chi square analysis of family member feelings revealed a trend for men to report feelings of anger more often than females $\left(X^{2}=2.98\right.$, df $\left.=1, p=.08\right)$. the arrival of the emergency personnel with lights and/or sirens, disrespectful personnel, and multiple people in the home were associated with feelings of anger (Table 3). Cramer's phi for each of these relationships shows the greatest strength between anger and use of lights and/or sirens with a value of 0.69 and anger with disrespectful personnel, which had a phi of 0.80 .

Due to the small sample size of the respondents $(n=2)$ who witnessed the transport of a body for death determination, no conclusion about the results can be made other than to note that the respondents indicated that they thought the transport was legally necessary and the circumstances made them feel very sad.

The events surrounding the death have not faded for the family members after two to ten months. Most of the family members report continuing to think about that day ( 97 percent). In fact, 76 percent indicated that they think it is important to remember that day. Feelings of anger about the arrival of emergency personnel were significantly associated with continuing thoughts about the day of the death $\left(\mathrm{X}^{2}\right.$ $=3.80, \mathrm{df}=1, \mathrm{p}=.05$ ).
Legislation to allow nurses to determine death in the home for home care clients who die of a diagnosed terminal illness is already in place in a few states.

\section{Relationship of the demographic variables}

The review of the literature on attitudes about death suggested that there might be demographic variables for family members or the deceased that could be related to attitudes about death determination practices (Tables 4 and 5). Investigation of these demographic variables revealed significant differences only between individual characteristics and feelings about the death 


\begin{tabular}{lccc|} 
Table 4. Characteristics of respondent family members (N=53) & \\
Characteristic & n(Percent) & Characteristic \\
Sex (n=53) & & Age (years) & $(\mathrm{n}=53)$ \\
Male & $14(26.0)$ & Range & $15-78$ \\
Female & $39(74.0)$ & Mean & 50 \\
& & Median & 51 \\
Relationship to deceased $(\mathrm{N}=53)$ & & \\
Spouse & $31(58.8)$ & \\
Daughter & $13(24.5)$ & \\
Son & $3(6.0)$ & \\
Other & $6(11.0)$ & \\
& & \\
Highest level of education $(\mathrm{n}=52)$ & & \\
Less than high school & $4(8.0)$ & \\
High school & $24(46.0)$ & \\
Associate degree & $10(19.0)$ & \\
Baccalaurea & $8(15.0)$ & \\
Graduate degree & $6(12.0)$ & \\
& & \\
Religion (n=41) & & \\
Catholic & $19(46.0)$ & \\
Protestant & $18(44.0)$ & \\
Other & $4(10.0)$ & \\
None & $0(0.0)$ & \\
\hline
\end{tabular}

Table 5. Charcteristics of deceased as described by family member $(\mathrm{N}=53)$

\begin{tabular}{lrrr} 
Characteristic & $n$ (Percent) & Characteristic \\
& & Rength of illness (months) \\
Illness & $51(96.0)$ & Mean & $1-60$ \\
$\quad$ Cancer & $2(4.0)$ & Median & 17 \\
Other & & & \\
& & \\
Length of time requiring extra care & $2(4.0)$ & \\
Less than 1 week & $6(11.0)$ & \\
1 to 3 weeks & $13(25.0)$ & \\
1 to 3 months & $24(45.0)$ & \\
4 to 12 months & $8(15.0)$ & \\
More than 1 year & & \\
Time since death & $30(57.0)$ & \\
2 to 5 months & & \\
\hline
\end{tabular}

event for the feeling of relief. Family members with a high school education or less were more relieved to have fire, police or emergency personnel $\left(\mathrm{x}^{2}=6.58, \mathrm{df}=1, \mathrm{p}=.04\right)$ than those family respondents who had advanced education. Also, there were significant differences in reported feelings of relief based on the length of family member illness ( $U=6.5, p=.02$ ).

\section{Written comments}

Some idea of how much impact the death event had on the life of family member can best be illustrated by the responses to the last item of the questionnaire, an invitation to share additional thoughts, comments or concerns. Thirty-seven (70 percent) of the family members wrote comments. The comments were focused on two major themes:
- feelings about the arrival of emergency personnel and

- thought about the day of death in general.

Most of the comments about the arrival of police, fire, and emergency personnel were explanations of their feelings of anger. They described it as "an invasion of privacy; rude and intrusive; shock at the strangers in your home; made me feel guilty, implying that something had been going on; people barged in like locus (sic); too many people; too many unnecessary questions; or took away the dignity of my mother." Those who had not indicated either guilt or a bothered feeling indicated that it would have been helpful to them to have been warned in advance that the police would come to the home.

The remainder of the written comments reviewed the day of the death and survivor feelings. Most respondents added a note of thanks to the individual home care agencies (never could have done it without them) and to their individual nurse's (tower of strength, saint, comfort). Several survivors mentioned the fact that the choice to die at home had been that of the deceased. Several also mentioned the difficulty of caring for someone with a slow, deteriorating illness. The mother of a child who died described remembering a police officer cry. Each explicitly added incredible detail to their description of the death.

\section{Discussion}

The data in this study reflected a diversity of death determination practices. There clearly is no single practice for the determination of death at home. It appears that any one or a combination of individuals (nurse, doctor, medical examiner, police, fire or emergency personnel) may attend or respond to a death in the home.

The family members who shared their feelings about the arrival of emer- 
gency personnel most often reported feelings of sadness. The reaction of relief and anger was reported with slightly less frequency. Over one-third of the family members said the arrivals were bothersome. They attributed this feeling to the sight of the vehicles outside the home, the questioning process, the use of lights and sirens, and the number of people coming to the home.

One outstanding characteristic of

\section{One outstanding characteristic of surviving family members in this study was the intensity of their memory of the circumstances surrounding the death two to ten months after the experience.}

surviving family members in this study was the intensity of their memory of the circumstances surrounding the death two to ten months after the experience. In this study, the reaction of anger was significantly associated with continuing vivid memories of the day of the death.

The relief reported by family members at the arrival of fire, police and emergency personnel was an unexpected result. It is not clear how the word relief was interpreted or why family members with high school or less education reported significantly more relief. The reports of relief may be related to that fact that the family members no longer had to deal with the suffering of seriously ill family members. It might be that this group was uncomfortable with the body in the home for a length of time (usually over one hour) without the support or assistance of a professional or simply unsure what to do at the time. Or, it may be that these family members attached significance to the actual pronouncement of death which is not actually occurring until an hour or two after the actual death.

\section{Implications for practice and conclusion}

An important opportunity exists for nurses to share their knowledge about the impact of the death experience on families with physicians and emergency personnel. Nurses need to share with emergency personnel (especially police since they respond to the death most frequently) what they observe in families where arrival and/or transport occurs. They need to be sensitive to the family feelings of sadness, relief, and anger. They need to know that lights, sirens, questions, and large number of personnel arouse angry feelings.

Pine suggested that survivors tend to re-examine the circumstances leading to death and reconstruct those past situations in an attempt to achieve order during the bereavement period. ${ }^{19}$ Respondents to this questionnaire supported Pine's findings. Bereavement counseling by nurses or others must take into account that survivors have vivid memories of the day of death after ten months. Survivors' feelings of anger at intrusions are associated with increased continuing thoughts of the day of death.

Legislation to allow nurses to determine death in the home for home care clients who die of a diagnosed terminal illness is already in place in a few states. It could be a powerful strategy since it would prevent the arrival and transport by emergency personal when the nurse is present at the time of death. $\square$

\section{References}

1. Griffith, E: The home health agency: past, present \& future. Caring 1986; 5(8): 12-15.

2. Michigan Public Act 1979; 124, Sec. 2843. 3. Benoliel, J: Nursing research on death, dying, and terminal illness: Development, present state, and prospects. (IN) H. Werley \& J. Fitzpatrick (eds.): Annual review of nursing re- search, 1983: 101-130.

4. Woodhall, C: A family concern. Nursing Times 1986; 82(43): 31-33.

5. Kirschling, J: Support utilized by care givers of terminally ill family members: Clinical implications for hospice team members. The American Journal of Hospice Care 1985; 2(2): 27-31.

6. Cameron, J. \& Parkes, C: Terminal Care: evaluation of effects on surviving family of care before and after bereavement. Postgraduate Medical Journal 1983; 59: 73-78.

7. Ferrell, B: Cancer deaths and bereavement outcomes, home versus hospital. The American Journal of Hospice Care 1985; 2(4): 18-23.

8. Sanders, C: A comparison of adult bereavement in the death of a spouse, child and parent. Omega 1979; 10: 303-321.

9. Parkes, C: Bereavement. British Journal of Psychiatry 1985; 146: 11-17.

10. Sudman, S. \& Bradburn N: Asking questions. San Francisco, California: Jossey-Bass, Inc., 1982.

11. Bugen, L: Human grief: Amodel for prediction and intervention. (In) L. Bugen (ed.): Death and dying: Theory, research, practice. Dubuque, Iowa: Wm. C. Brown, 1979.

12. Pollock, G: Anniversary reactions, trauma, and mourning. Psychoanalytic Quarterly 1979; 39: $347-371$.

13. Mintz, I: The anniversary reaction: A response to the unconscious sense of time. Journal of the American Psychoanalytic Association 1971; 19: 720-735.

14. Kane, R., Klein, S., Bernstein, L. \& Rothenberg, $R$ : The role of hospice in reducing the impact of bereavement.

15. Lunding, T: Long-term outcome of bereavement. British Journal of Psychiatry 1984; 145: 424-428.

16. Michigan Hospice Organization, personal communication, April 8, 1987.

17. Michigan Department of Public Health: Deaths, county and hospital of occurrence, by month. Lansing: Author, 1980, 1986.

18. Ajzen, I. \& Fishbein, M: Understanding attitudes and predicting social behavior. Englewood Cliffs, New Jersey: Prentice-Hall, Inc., 1980.

19. Pine, V: Dying, death and social behavior. (In) B. Schoenberg, A. Carr, A. Kutscher, D. Peretz \& I. Goldberg (eds.), Anticipatory grief, New York: Columbia University Press, 1974: 31-46

\section{Acknowledgments}

The author gratefully acknowledges the funding provided by the American Cancer Society-Michigan Division, Nursing Study Grant. Additionally, the expertise provided by Deborah Oakley, $P h D$ and Susan Clemen-Stone, MPH, RN was helpful beyond measure. 